\title{
Impact of Eating Habits and Lifestyle on the Oral Health Status of a Casablanca's Academic Population
}

\author{
Houriya Mestaghanmi1 ${ }^{*}$, Ali Labriji ${ }^{2}$, Imane M'Touguy ${ }^{1}$, Fatima Zahra Kehailou${ }^{1}$, Said Idhammou ${ }^{1}$,

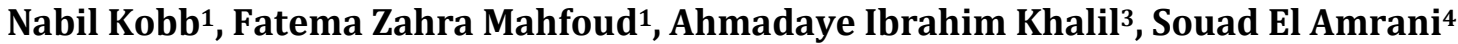

\author{
${ }^{1}$ Metabolism Nutrition Toxicology Team, Physiopathology and Molecular Genetics Laboratory, Biology Department, Ben M'Sik \\ Sciences Faculty, Hassan II-Casablanca University, Casablanca, Morocco \\ ${ }^{2}$ Laboratory of Analysis Modelisation and Simulation, Department of Mathematics and Information, Faculty of Sciences Ben \\ M’Sik, Hassan II-Casablanca University, Casablanca, Morocco \\ ${ }^{3}$ Cancer Registry of Greater Casablanca, Casablanca, Morocco \\ ${ }^{4}$ Ecology and Environment Laboratory, Biology Department, Ben M’Sik Sciences Faculty, Hassan II-Casablanca University, \\ Casablanca, Morocco \\ Email: ^h.mestaghanmi@gmail.com, alilabriji@gmail.com, brahimahmadaye@yahoo.fr, selamrani_1999@yahoo.fr
}

How to cite this paper: Mestaghanmi, $\mathrm{H}$., Labriji, A., M’Touguy, I., Kehailou, F.Z., Idhammou, S., Kobb, N., Mahfoud, F.Z., Khalil, A.I. and El Amrani, S. (2018) Impact of Eating Habits and Lifestyle on the Oral Health Status of a Casablanca's Academic Population. Open Access Library Journal, 5: e4967.

https://doi.org/10.4236/oalib.1104967

Received: October 8, 2018

Accepted: October 29, 2018

Published: November 1, 2018

Copyright $\odot 2018$ by authors and Open Access Library Inc.

This work is licensed under the Creative Commons Attribution International License (CC BY 4.0).

http://creativecommons.org/licenses/by/4.0/

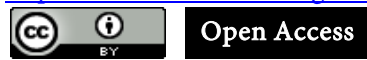

\begin{abstract}
Introduction: Bad eating habits can have serious impact on oral health. Objectives: To study the impact of eating habits and dental hygiene practices on the dental status of students. Methods: Cross-sectional study of 400 students aged 17 and more, from the Ben M'Sik Sciences Faculty. A questionnaire on the socio-economic level of the parents, the eating habits, the means of hygiene and the oral health status has been filled in anonymously by the respondents. Univariate and multivariate descriptive and comparative analyzes were performed by the software SPSS 21 . Results: The population's average age is $20 \pm 1.59$ years old consisted of $55 \%$ of boys and $45 \%$ of girls. The breakfast is consumed by $67 \%$ of students. $39.58 \%$ respondents consume sweetened drinks during the meals and $60 \%$ at the end of meals and $66 \%$ are snacking during the day. $92 \%$ of students say they brush their teeth. The brushing time varies between 1 and 3 minutes. 37\% of students do never consult a dentist and $63 \%$ in case of dental problems. The prevalence of caries is $66 \%$. There is a positive association between the prevalence of tooth decay and certain eating habits (sweet things consumption $(\mathrm{p}=0.08)$, cakes $(\mathrm{p}=$ $0.018)$ and chocolate $(\mathrm{p}=0.019)$ outside of meals). However, this correlation is negative, when the consumption of these foods is done during meals ( $\mathrm{p}>$ $0.74)$. On the other hand, there was no correlation between alcohol consumption and presence of caries $(\mathrm{p}=0.172)$, tobacco consumption $(\mathrm{p}=0.319)$, and socioeconomic status parents $(\mathrm{p}=0.733)$. Conclusion: Oral hygiene and reg-
\end{abstract}


ular monitoring by a dentist with healthy eating habits can have a significant impact on the oral status of students.

\section{Subject Areas}

Nutrition, Public Health

\section{Keywords}

Students, Eating Habits, Snacking, Hygiene, Oral Health

\section{Introduction}

Eating habits define the type and quantity of food consumed by one or a group of people in their daily lives, as well as the frequency of these drinks. Healthy eating habits are impacting a good oral health status.

Oral health is an integral part of overall health and is essential to the well-being [1] [2]. It can have repercussions, sometimes severely, on the general condition and the life's quality of the people who suffer from it. Bad oral health can affect the appearance and self-esteem [3] [4].

Oral health influences the quality of life of the subject. Severe caries causes pain and disrupts sleep, which affects the overall health and performance and success of students.

An overall improvement in oral health has been noticed in our societies over the last thirty years. This could be explained by the improvement of oral hygiene (brushing quality and regular use of fluorides), the ease of access to dental care as well as the establishment of prevention and promotion systems of oral health [5].

The eating behaviors of different populations have evolved. We have moved from consuming fresh produce to processed products which affect overall health. Currently, we tend to adopt a diet rich in sugars and lipids, with a decline in physical activity [6]. The power supply has a great influence on oral health. Any food intake is likely to trigger the carious process [7], especially if it is accompanied by poor dental hygiene, because with a bad or no brushing, the sugars remain long contact with teeth and especially for some foods (candy...). Nevertheless, some foods or drinks are more cariogenic (sucrose and/or other fermentable carbohydrates...). The fermentation of common dietary carbohydrates leads to the production of demineralizing acids, under the action of the bacterial flora which accumulates in the dental plaque, on the sides and in the dental cracks [8].

The evolution of lifestyles, lack of time and the deconstruction of the meal helped snacking, with consumption of snacks and sugary drinks. However, the frequency of consumption remains the most important factor in the installation of decay. More ingestions are repeated, more acid production is frequent and 
prolonged; the saliva buffering capacity is overwhelmed and balance demineralization/remineralization and broken [9]. Tooth decay is extremely common. According to the W.H.O., it remains the third world scourge in terms of morbidity, after cancer illnesses and cardiovascular disease. It is defined as specific tooth discoloration. It is a multifactorial disease in centripetal evolution, during which the various factors to cause the irreversible destruction of tissues mineralized tooth [10]. "Caries process" can be stopped or potentially reversed at all early stages of disease development, but most of the time, it extends gradually and without correct hygiene and care, it progresses up to the destruction of the dental organ [11]. The decay can be a real public health problem [12]. Although, all age groups are affected and in very diverse clinical forms, the more frequency varies between different populations, different individuals and sometimes in the same individual over time. In Morocco, the decay rate is $81.8 \%$ among children of 12 years and $91.8 \%$ among 35-44-year olds. For these reasons the Department of health has developed a new strategic plan for the period 2018-2025, to continue efforts to improve the oral health of citizens and which aims to reduce the prevalence of caries and parodontopathies of 30\% among groups [13]. Students are a population at risk especially with the peculiar lifestyle and consumption of unbalanced meals. The risk of caries is increased by snacking throughout the day and especially with food sweet between meals. However, there are very few studies on the prevalence of dental caries among students who are also concerned by the evolution of eating habits and their significant impact on oral health. It is in this context that this work, given the importance of this topic on the well-being and performance of students, whose main objective is to study the impact of eating habits, knowledge dental hygiene and State of health oral. While the specific objectives are to study:

- Eating habits of the students of the Ben M' Sik's Sciences Faculty.

- The hygiene practices and dental care.

- The caries prevalence and its association with eating habits, hygiene and dental care.

\section{Methodology Used}

\subsection{Type and Location of the Study}

A descriptive cross-sectional survey was conducted by means of a questionnaire with a population of 400 students from the Ben M'Sik's Sciences Faculty. This faculty is part of Hassan II University. It offers on its campus training in several districts and provinces of Casablanca. During the year 2016-2017, it was attended by approximately 11,500 students. They don't have a university restaurant, but only a cafeteria.

\subsection{Criteria for Inclusion and Exclusion}

Have been included in this study all students volunteer enrolled in the Ben M'Sik's Science Faculty during the 2016-2017 academic's year, from all streams 
and levels of study. Students from the other faculties of Casablanca were excluded from this study.

\subsection{Sampling}

To facilitate the recruitment of respondents, announcements with contact information for the investigators were posted at the faculty. A schedule was established and direct contact between student investigators and those wishing to participate in the survey took place after they gave their informed consent.

\subsection{Data Collection Instrument}

The anonymous questionnaire was distributed to 400 students. It consisted of 34 items, grouped into several components (socioeconomic level of parents, eating habits, frequency and timing of foods consumed, dental hygiene (brushing teeth, technique used, frequency and timing of brushing)) with the prevalence of tooth decay. In order to ensure a good understanding of all the questions, especially the open ones, a preliminary interview was conducted with the respondents.

To validate the questionnaire, a pre-test phase was carried out during which the sample chosen consisted of about fifty people with age, sex, pathways, education level and socio-economic status different.

\subsection{Variables Studied}

Several variables were studied:

- Socio-demographic factors (age, sex, socio-economic status of parents...). The socioeconomic level of the parents was assessed based on their place of residence and level of education. 4 categories of education level (no: for those who have never studied, primary: studies from 1 to 6 years, secondary: studies from 6 to 12 years and higher for those who have completed more than 12 years of study), and the place of residence (villa, modern or traditional house, apartment or other (slum)) were defined. For income, it was difficult to get information from the respondents.

- The eating habits (time of consumption of some foods, nibbling, snacks...).

- Lifestyle (consumption of alcohol, tobacco or drugs) that have an impact on the state of oral health-Oral health: knowledge, dental status, hygiene, dental care and type of medical coverage.

From the results obtained, we have calculated the actual percentage of teeth treated on all the teeth requiring a treatment that is given by the report [14]:

$100^{\star}$ Closed teeth/(Decayed + closed teeth $)$.

\subsection{Statistical Analysis of the Results}

The data collected was captured and analyzed using SPSS software, version 21 . This software allows the calculation of significativities, averages and standard deviations. The Pearson Khi2 test allows comparison between different groups. The result is considered significant when $\mathrm{p}<0.05$. The Odds Ratio was also cal- 
culated as well as the confidence intervals.

\section{Results}

\subsection{Socio-Economic Data}

- The population is made up of $55 \%$ of girls and $45 \%$ of boys, $87 \%$ of whom are between 17 - 23 years old; $10 \%$ between 24 - 26 years old and 3\% are over 26 years old. $87 \%$ of the students follow their studies in License, $8 \%$ in Master and $5 \%$ in $\mathrm{PhD}$. The slight over representation of girls in the population is related to the higher number of girls enrolled in the faculty.

- $47 \%$ of students report living in a detached house (modern or traditional); $44 \%$ live in apartments; $3 \%$ in villas and $6 \%$ live in other types of housing (slums...).

- $19.64 \%$ of parents have a higher education; $33.04 \%$ have a high school level; $30.36 \%$ have a primary level and 16.96 are illiterate.

\subsection{Students' Eating Habits}

\subsubsection{Consumed and Skipped Meals during the Day}

The results show that breakfast is not consumed by all students. $35 \%$ of which $20 \%$ of girls and $15 \%$ of boys still take it and $32 \%$ often of which $19 \%$ are girls and $13 \%$ are boys. $27 \%$ rarely (17\% girls and $1 \%$ boys), and $6 \%$ never, with a slight difference between the two sexes (Khi2 $=2.357, \mathrm{p}=0.05$ ). However, this meal is only balanced and structured for $32 \%$ of the respondents. It is also the most jumped meal. $17.2 \%$ of respondents still skip it. However, $57.3 \%$ of respondents say they have never skipped lunch. It is consumed by $66 \%$ of students $(34 \%$ always and $32 \%$ often). On the other hand, $45 \%$ never skip dinner but $41 \%$ skip it by desire for weight loss, while $26 \%$ of students, it is a meal that is not important.

It is also noted that the cause of meal jumps (breakfast and lunch) is the lack of time for many students (69\%). However, $31.4 \%$ say that it is because of the poor quality of food marketed at the cafeteria's faculty.

\subsubsection{Food Eaten at the End and between Meals}

\section{1) Food consumed at the end of meals}

The carious process can be either favored or slowed down depending on the foods eaten at the end of the meal. Thus, some foods are cardioprotective (water, dairy products, vegetables, etc.), other cariogenic (sweet drinks, candies, etc.). At the end of the meal, most students say they consume an abundance of fruits $(48 \%)$, water (16\%), yogurts (6\%), sweet drinks (25\%) and chocolate (5\%).

\section{2) Consumption of sweet foods}

\section{Sweet drinks during and outside meals}

- $92 \%$ of students report consuming sweet drinks at least once a day and $8 \%$ at least 3 times/day. However, the consumption of drinks during meals is generally low (39.58\%). Thus, $18.06 \%$ of students are used to consuming soft drinks and $9.24 \%$ consume juices. In contrast, water is consumed by more than half of the respondents ( $58 \%$ tap water and $2.52 \%$ mineral water). 
- While outside meals, water consumption is the dominant (50.44\%) (41\% tap water and $9.44 \%$ consume mineral water), while that of other drinks remains low. Thus, $14.44 \%$ of students are used to consuming soft drinks and $15.93 \%$ are fruit juice. $15 \%$ consume tea and $14.19 \%$ coffee or latte.

In contrast, the drink most consumed by respondents after dinner is water $(82 \%)$, while tea $(12.54 \%)$ and fruit juice $(7.22 \%)$ are only slightly consumed. idem for soft drinks (9\%).

Consumption of confectionery (sweets, chocolate...) and addition of sugar to already sweet foods

- The frequency of consumption of confectionery during the day varies according to the different types. Generally, $42.7 \%$ of students never consume them, $30.7 \%$ of students consume them 1 to 3 times/day; $11.9 \% 3$ to 6 times/day; $14.7 \%$ more than 6 times/day, this is the case of chocolate/chocolate bars which comes in first place followed by soft candy and chewing gum.

- $38 \%$ of students say they add sugar to foods or beverages that are already sweet, while $62 \%$ do not add it.

\subsubsection{Nibbling and Snacks}

\section{1) Nibbling}

$25 \%$ of students still nibble (13\% of girls and $12 \%$ of boys), $41 \%$ often ( $25 \%$ of girls and $16 \%$ of boys), $25 \%$ rarely (10\% of girls and $15 \%$ of boys), no difference between the two sexes ( $\mathrm{khi} 2=4.842, \mathrm{p}=0.184$ ), nor according to the age of the respondents $(\mathrm{khi} 2=6.638, \mathrm{p}=0.675)$.

The most nibbled foods during the day are chocolate and chocolate bars (16\%), soft- and hard-boiled sweets (12\%), chips, fresh or dried fruits (10\%), chewing gum (10\%), yogurt $(8 \%)$ or cakes $(8 \%)$ are cited by few students.

It should also be noted that students nibble more in the evening than during the day (75\%), especially when reviewing their course. The most nibbled foods at night are the same as those nibbled during the day (chocolate/chocolate bars, chips, fresh or dried fruit, cakes and yogurts).

\section{2) Snacks}

Many students (42\%) often take a snack, $21 \%$ still and $36 \%$ report taking it seldom and only $1 \%$ of students never take it. These snacks are consumed most often in Fast Food (40.15\%), while (34.8\%) students take them at home and (25\%) at cafeterias. $33.5 \%$ take a morning snack, $32 \%$ in the afternoon and $15 \%$ in the evening (Table 1 ).

The morning snack consists mainly of pastries (23\%), cheese (11\%), tea (32\%), milk (8\%), fruit (12\%) or biscuits (14\%).

Students also seem to consume more food in the evening than in the morning. The most consumed foods at night are fruit (27\%), pizzas and salty cakes (20\%), chocolate (29\%), fruit juice (20\%) and lemonade (26\%).

\subsection{Lifestyle}

- In all the study population, $5.3 \%$ consume tobacco (all boys). $57 \%$ are be- 
tween 20 and 22 years old, 38\% are between 22 and 24 years old and 5\% between 24 and 26 years old. $33.3 \%$ of smokers consume 12 or more cigarettes per day, 19\% between 10 and 12 cigarettes, 19\% between 8 and 10 cigarettes. $38 \%$ of smokers started to smoke between the ages of 16 to 18 years old, $33 \%$ between the ages of 18 to 20 and $19 \%$ to 20 years old and over.

- $6 \%$ of our respondents are alcohol consumers and all are boys, $41 \%$ of them are between 20 and 22 years old, 33\% between 22 and 24 years old, $12.5 \%$ between 24 and 26 years. However, $71 \%$ of alcohol consumers consume it occasionally, $21 \%$ consume it once a week, and $4 \%$ consume it several times a week, $4 \%$ consume it once a month. Finally, $92 \%$ say they are addictive and addicted to alcohol and can't stop using it.

\subsection{Oral Health of Students}

\subsubsection{Student Knowledge}

All students present knowledge about the nature of foods that can influence oral health. Thus, $70 \%$ of them say that the most cariogenic foods are chocolate/honey/jam (40\%), baked goods (41\%). However, the opinions of the rest of the population are divided between fruit and juice (19\%).

The majority of respondents (65\%) report that good dental hygiene is essential to prevent cavities. However, for $35 \%$ of respondents it is necessary to eat balanced to avoid this disease. However, $23 \%$ of students have no idea about oral diseases. The disease they know best is tooth decay (55\%).

\subsubsection{Dental Status}

The study population has a caries attack prevalence of $66 \%$. Indeed, each of the respondents has at least tooth decay. This prevalence varies by sex and is higher for girls (37\%) than for boys (29\%), but with no significant difference between the two sexes (Khi2 $=0.088, \mathrm{p}=0.460$ ) (as shown in Table 1 ).

$30 \%$ have missing teeth, including $18 \%$ one tooth, $8 \%$ two teeth, $3 \% 3$ teeth, and $1 \% 4$ teeth, with significant difference between the different groups (Khi2 = $100, \mathrm{p}=0.00$ ). $32 \%$ have closed teeth (tooth with caries) of which $14 \%$ tooth, $10 \%$ two teeth and $8 \% 3$ teeth, with a significant difference between the different groups $($ Khi $2=17.764, \mathrm{p}=0.001)$.

Table 1. Table showing the distribution of the Breakdown of students according to their dental status.

\begin{tabular}{ccccccc}
\hline Variables & 1 tooth & $\mathbf{2}$ tooth & $\mathbf{3}$ tooth & $\mathbf{4}$ tooth & $\mathbf{5}$ tooth & Total \\
\hline $\begin{array}{c}\text { Closed teeth } \\
\text { Yes }\end{array}$ & $14 \%$ & $10 \%$ & $8 \%$ & $0 \%$ & $0 \%$ & $32 \%$ \\
No & - & - & - & - & - & $68 \%$ \\
Missing teeth & & & & & & \\
Yes & $18 \%$ & $8 \%$ & $3 \%$ & $1 \%$ & - & $30 \%$ \\
No & - & - & - & - & - & $70 \%$ \\
\hline
\end{tabular}


Only $6 \%$ of respondents wear a dental appliance with $81.7 \%$ who clean it every day, against $18.3 \%$ who clean it sometimes.

The actual percentage of closed teeth (on all teeth requiring care) is given by the ratio: $100 \times$ Substituted teeth/(Decayed + closed teeth). It follows that the actual percentage of teeth treated on all teeth requiring treatment is $32.65 \%$.

\subsubsection{Dental Hygiene Practices}

We have differentiated between those who use the toothbrush and toothpaste (with frequency and regular brushing), and those who replace brushing with rinsing, floss, chewing gum, Swak (traditional toothbrush stick...).

$92 \%$ of students say they brush their teeth with a toothbrush and toothpaste. $78 \%$ use a toothpaste rich in fluorine and $10 \%$ use another type of toothpaste.

Among students who use the toothbrush, $41 \%$ brush their teeth twice a day, $35 \%$ once, only $11.2 \%$ brush their teeth three times a day and $4.8 \%$ recognize brushing their teeth more than three times a day. $21 \%$ for 3 minutes, $34 \%$ for 2 minutes and $45 \%$ of students brush their teeth for 1 minute. $53 \%$ take less than half an hour after the end of the meal to brush their teeth, $17 \%$ take more than 30 minutes and the rest of the students (22\%) say that the time between brushing and the end of the meal is not important.

For the brushing technique, $67 \%$ use the toothbrush and the toothpaste, $20 \%$ perform a rinsing with water, while $13 \%$ use other techniques that are brushing additives (dental floss, chewing gum, swak...).

When respondents are not available to brush their teeth, $36 \%$ of respondents opt for a rinse with water, $29 \%$ use a chewing gum without sugar, against $16 \%$ who opt for a sweet chewing gum, $12 \%$ do nothing to replace brushing.

For some students, the preferred brushing time is after dinner (40.9\%). While the most overlooked moment is after snacks (28.6\%) and after lunch (18\%), followed by the moment after breakfast (12.5\%), with no significant difference between skipped brushing moments $(\mathrm{p}<0.05)$.

The average number of toothbrushes used during the year by our respondents is $3.98 \pm 0.81$ with a minimum of one toothbrush and a maximum of 7 toothbrushes. This corresponds to an average renewal of brushes every two months.

\subsubsection{Consumption after Brushing}

$45 \%$ of students report eating after brushing their teeth at night. Most eat fruit (20\%). This practice cancels the effect of tooth brushing and promotes the process of demineralization.

\subsubsection{Dental Care and Types of Medical Coverage}

- $37 \%$ of students never consult a dentist and $63 \%$ only in case of dental problems, of which $50 \%$ occasionally and $13 \%$ periodically.

- Generally, students usually consult the private sector (87\%) and $12 \%$ consult the public sector and only $1 \%$ have access to both sectors. Unfortunately, most students have no medical coverage (56\%), and only $44 \%$ have it, of which $18 \%$ have CNSS and $26 \%$ have other medical coverage. 
- There is a statistically significant relationship between the prevalence of dental caries among students and the consumption of some foods after meals:

- Candies (Khi2 $=7.025, \mathrm{p}=0.08, \mathrm{OR}=0.818)$.

- The cakes: $(\mathrm{Khi} 2=5.62, \mathrm{p}=0.018, \mathrm{OR}=3.51)$.

- Chocolate bars/chocolate $(\mathrm{p}=5.49, \mathrm{p}=0.019, \mathrm{OR}=0.31)$.

- Lemonade: $($ Khi2 $=9.796, \mathrm{p}=0.02)$.

- Fruit juice (Chi2 = 3.62, $\mathrm{p}=0.049, \mathrm{OR}=2.63$ ).

However, no significant associations were observed when students consumed fruit (Khi2 $=0.257 ; \mathrm{p}=0.612)$, dried fruits (Khi2 $=2.939 ; \mathrm{p}=0.086)$, chips (Khi2 $=0.297 ; \mathrm{p}=5,88)$, pancakes (Khi2 $=0.304 ; \mathrm{p}=0.581)$, yoghurt $($ Khi2 $=0.35, \mathrm{p}=$ $0.554)$, tea (Khi2 $=0.01, \mathrm{p}=0.921)$, coffee (Khi2 $=0.06 ; \mathrm{p}=0.937$ ) and coffee with milk (Khi2 $=1.051 ; \mathrm{p}=0.305)$.

On the other hand, this correlation is negative, when the consumption of these foods is done during meals and therefore does not influence the carious process $(\mathrm{p}>0.74$; Khi2 $=5.95)$.

A negative association was also observed between alcohol consumption and presence of caries (Chi $2=1.868, \mathrm{p}=0.172$ ), tobacco consumption (Chi2 $=0.991$; $\mathrm{p}=0.319)$, regardless of the number of cigarettes consumed per day (Khi2 = $6.00, \mathrm{p}=0.112)$ as well as the socioeconomic level of parents (Khi2 $=1.284 ; \mathrm{p}=$ 0.733).

A negative association was found also between alcohol consumption and presence of caries $(\mathrm{Chi} 2=1.868 ; \mathrm{p}=0.172)$, tobacco consumption $(\mathrm{Chi} 2=0.991$; $\mathrm{p}=0.319)$, regardless of the number of cigarettes consumed per day (Khi2 = $6.00, \mathrm{p}=0.112$ ) as well as the socio-economic level of parents (Khi2 $=1.284 ; \mathrm{p}=$ $0.733)$.

No significant difference was found between caries prevalence and parental socioeconomic status (Khi2 $=1.284 ; \mathrm{p}=0.733$ ).

We note that of the $56 \%$ of students with no medical coverage, (43\%) have dental caries compared with only $13 \%$ who do not, with a significant difference between the two groups ( $p=0.010$ ) and a strong correlation between the two variables.

\section{Discussion}

The study was conducted on the impact of some eating habits, knowledge and lifestyle on the oral health student's status of the Ben M'Sik Science Faculty.

For the student's eating habits, our results revealed that breakfast is only consumed by $67 \%$ of students, $35 \%$ of them take it always and only $32 \%$ of students take a structured and balanced breakfast. It is also the most jumped meal. While it is a meal that allows build the forces necessary to effectively face the day. The quality of this first meal directly affects the physical and intellectual performance of the day. Beyond its nutritional role, breakfast is a special challenge for maintaining family ties; after dinner, it is the most common meal with the family.

At the end of the meal, most students say they consume an abundance of 
fruits (48\%), water (16\%), yogurts (6\%), sweet drinks (25\%) and chocolate (5\%). The food consumed by our students is similar to that consumed by Algerian students [15]. Sugary foods consumed in abundance at the end of meals present a risk to oral health. Thus, the fruits are the most consumed by the students. They are rich in fiber and nutrients. Only, it is necessary to consume them at the beginning of the meals, so that they can absorb the saturated fats consumed. By cons, when consumed at the end of meals, the bolus in the stomach will block the fruit and its nutrients that will be destroyed by stomach acids and therefore the subject will not take advantage of the vitamins and minerals of these foods. In addition, the presence of sugar in fruits has a cariogenic power, so you must brush your teeth after each meal.

Our students also consume at the end of the meal yogurt (6\%), sweet drinks (25\%) and chocolate (5\%). In general, for the latter, if it is rich in cocoa and low in sugar, it has a protective curry effect. Yogurts are a source of protein and calcium, while sugary drinks with a high caloric content promote obesity and increase the prevalence of metabolic diseases such as diabetes and cause tooth decay [16]. The drinks are also acidic. Indeed, the beverage industries generally add phosphoric or citric acid, to camouflage sugar. This acidity will lead to demineralization of tooth enamel.

$57.3 \%$ of respondents say they have never skipped lunch. It is consumed by $66 \%$ of students ( $34 \%$ always and $32 \%$ often). On the other hand, $45 \%$ never skip dinner. On the other hand, $41 \%$ jump it to lose weight, whereas for $26 \%$ of students, it is a meal that is not important. So, the three meals are not often taken by some students. The jumps of the meals push them to nibble along the day. Thus, $25 \%$ of students still nibble (13\% of girls and $12 \%$ of boys), $41 \%$ often ( $25 \%$ of girls and $16 \%$ of boys), $25 \%$ rarely ( $10 \%$ of girls and $15 \%$ of boys), without significant difference between the two sexes (Khi2 $=4.842 ; \mathrm{p}=0.184$ ), and between the age of the respondents (Khi2 $=6.638 ; \mathrm{p}=0.675)$.

The most nibbled foods during the day are chocolate and chocolate bars (16\%), soft- and hard-boiled sweets (12\%), chips, fresh or dried fruits (10\%), chewing gum $(10 \%)$, yogurts $(8 \%)$ or cakes $(8 \%)$ which are cited by few students. They nibble more in the evening than in the day (75\%), especially when reviewing their course. The most nibbled foods at night are the same as those nibbled during the day.

Snacking is an eating disorder that consists of having several small food intakes, throughout the day, outside of mealtimes and snacks, and in addition to the latter, it goes against a diet balanced. Indeed, some students fail to consume balanced meals because of lack of time, as well as financial means. Snacking is often about filling a craving and not a hunger: you bring to the body sugars, fats and calories that are useless. The foods eaten are mainly fatty industrial foods and especially sweet: sweets, cakes, chips... which are easily eaten. These foods stimulate the area of reward and immediate pleasure in the brain. Indeed, the type, the shape and the consistency of a food have an impact on its cariogenic 
potential. The texture has a great importance on the duration of retention of the food in the mouth. In addition, the consistency of the food has an effect that can be either positive (sticky food such as caramel, cheese, etc.) or negative (dry biscuits) on stimulating the production of saliva [17].

$38 \%$ of students say they add sugar to foods or drinks that are already sweet, while $63 \%$ do not add it. This addition of sugar is likely to increase the risk of oral diseases. Different results were observed by Khaldi [15], who noticed that very few Algerian students added sugar to their meal (16.8\%). Johnson and Frary [18] showed the presence of a statistically significant association between the consumption of some foods after meals such as sweets, chocolate and cakes and the frequency of dental caries. It has been clearly established that carbohydrate foods play a major role in caries formation mechanisms: their cariogenic action is exerted directly on the surface of the teeth. Indeed, the cariogenicity of sugars is well known; in ascending order of cariogenic power we cite lactose, maltose, glucose, fructose and sucrose [19]. Sucrose is the most cariogenic carbohydrate. Bacteria use it to produce organic acids and synthesize polymers that promote bacterial adhesion.

Numerous epidemiological studies around the world have shown that the prevalence of caries in the twentieth century was low in populations that had a primitive lifestyle and a diet composed of local products containing little sugar. An increase in caries is systematically observed with the improvement of living conditions; individuals adopt "high-sugar", "civilized" food that includes ready-to-eat foods, snacks and treats available everywhere. These different considerations on the cariogenicity factors of food make it possible to establish a list of the most harmful foods for our teeth; their carious power being the combination of different parameters (sugar content, viscosity, texture among others).

$92 \%$ of students report consuming sugary drinks at least once a day and $8 \%$ at least 3 times/day. Indeed, with each sugar intake, the $\mathrm{pH}$ decreases in 5 minutes and persists below the critical threshold of 5.5 then, $\mathrm{pH}$ up after 20 minutes. Exhibitions at sugar for long periods of time will cause a continuous acidity; this decreases the effectiveness of the buffer capacity of saliva [17]. However, the consumption of drinks during meals is generally low (39.58\%). Thus, $18.06 \%$ of students are used to consuming soft drinks and 9.24\% consume juices. In contrast, water is consumed by more than half of the respondents (58\% tap water and $2.52 \%$ mineral water). Generally, liquids are quickly eliminated in the mouth and adhere only slightly to the tooth surfaces. While stronger foods like crisps are very adherent to tooth surfaces and can stay in the spaces between teeth [17]. On the other hand, outside meals, water consumption is the most important (50.44\%) (41\% tap water and $9.44 \%$ consume mineral water), while that of other drinks remains low. Thus, $14.44 \%$ of students are used to consuming soft drinks and $15.93 \%$ are fruit juice. $15 \%$ consume tea and $14.19 \%$ coffee or latte. These drinks are generally sweet and therefore are more or less cariogenic. Moreover, Stegeman and Davis [20] have shown that the most cariogenic drinks 
are alcohol, fruit juices as well as sugary drinks (lemonades, syrups, etc.).

It was also noted that after dinner, the drink most consumed by the respondents is water $(82 \%)$, while tea $(12.54 \%)$ and fruit juice $(7.22 \%)$ do not are only slightly consumed. Some students consume soft drinks (9\%). The consumption of water allows the body to hydrate, while the consumption of drinks especially sugars outside meals can present a risk for oral health. But generally, the cariogenic effect of food depends on their composition, but also on the timing and frequency of their consumption.

A prevalence of caries involvement of $66 \%$ was observed. It varies by sex. It is higher for girls (37\%) than for boys (29\%), but with no significant difference between the two sexes $(\mathrm{Khi} 2=0.088 ; \mathrm{p}=0.460)$. A similar prevalence has been observed by Kane et al. [21] among Senegalese students living in dormitories. It is more important for women (62\%). On the other hand, Esclassan [22] did not observe any significant differences between the two sexes in adult individuals of the medieval population.

$66 \%$ of students have at least one cavity. The frequency of dental caries among our students remains one of the health problems. This prevalence is still lower than that shown by studies conducted by the Ministry of Health, which revealed that dental caries affects $82.5 \%$ of adolescents over 15 , while the CAD index (or average number decayed, absent, or blocked teeth) is 4.30 in adolescents over 15 years old [23]. Nevertheless, Morocco, through the Ministry of Health, adopted a strategy to fight oral diseases as early as the end of the 1980s. It focused on two main axes, namely a preventive component in which information, education and communication are basic activities and a curative component oriented towards basic dental health care [24]. It therefore appears from the results of this work that this strategy is beginning to bear fruit.

A statistically significant association was observed between caries and the consumption of some foods (Candies (Khi2 = 7.025; $\mathrm{p}=0.08$; OR $=0.818$ ); Cakes: $($ Khi $2=5.62 ; \mathrm{p}=0.018 ; \mathrm{OR}=3.51))$ as well as chocolate bars/chocolate $(\mathrm{p}$ $=5.49 ; \mathrm{p}=0.019 ; \mathrm{OR}=0.31)$, Lemonades: (Khi2 $=9.796, \mathrm{p}=0.02)$ and fruit juices (Khi2 $=3.62 ; \mathrm{p}=0.049 ; \mathrm{OR}=2.63$ ). Moreover, several studies around the world have shown this association, according to Frank [25] and Dargent Pare and Levy [26], a food is cariogenic when it participates directly or indirectly in the risk of caries. Thus, foods that cause a drop in $\mathrm{pH}$ above a threshold are acidogenic and have a cariogenic potential. The cariogenicity of a food depends on its various constituents. But also, of the individual who ingests it, the quantity consumed, the time of ingestion, the frequency and the importance of oral retention. A cariogenic food consumed alone behaves differently from a cariogenic food consumed during a meal [23].

However, no significant associations were found between the presence of caries and the consumption of fresh fruit (chi2 $=0.257, \mathrm{p}=0.612$ ) or dried fruit (chi2 $=2.939 ; \mathrm{p}=0.086$ ). This could be related to the frequency of consumption of these foods. Whole fruits contain carbohydrates but also dietary fiber. Their 
acidity is neutralized by the production during chewing. Normally if the consumption of these fruits is reasonable, they are not very cariogenic.

Dental hygiene practice results show that almost all students brush their teeth (92\%). This result is almost identical to that of Algerian students (93\%) [15]. However, $32 \%$ of those who report toothbrushing have a habit of eating after brushing. This result is higher than that observed among Algerian students, only $20 \%$ of whom eat after brushing their teeth [15].

$78 \%$ use a toothpaste rich in fluoride and $10 \%$ use another type of toothpaste. In fact, low concentrations of fluorine can inhibit proliferation of caries and thus limiting the demineralization and remineralization increases. The fluorides also can inhibit the cariogenic bacteria metabolism [27].

$30 \%$ have missing teeth, including $18 \%$ one tooth, $8 \%$ two teeth, $3 \% 3$ teeth, and $1 \% 4$ teeth, with significant difference between the different groups $(\mathrm{Khi} 2=$ $100 ; \mathrm{p}=0.000$ ). $31 \%$ have closed teeth (tooth with caries) of which $14 \%$ tooth, $10 \%$ two teeth and $8 \% 3$ teeth, with a significant difference between the different groups (Khi2 = 17.764; $\mathrm{p}=0.001$ ).

The actual percentage of teeth treated all the teeth requiring treatment is $31 \%$. This percentage shows an improvement of the State of oral health in Morocco. Indeed, Belkaab [28] showed that in Morocco, treatment requirements were necessary in $34.1 \%$ of children of 12 years old, $51,6 \%$ of adolescents 15 years and $84.2 \%$ of adults aged 35 - 44 .

The average number of toothbrushes used throughout the year by our respondents is $3.98 \pm 0.81$. This corresponds to an average of renewal of brushes every two months. This result is consistent with the recommendations of the UFSBD [29], which advises to renew the toothbrush every three months. Unfortunately, the frequent renewal of toothbrushes requires financial means that some students do not have.

Among students who use the toothbrush, $41 \%$ brush their teeth twice a day, $30 \%$ once and only $11 \%$ brush their teeth three times a day and $4.8 \%$ recognize brushing their teeth over three times per day. With a twice-daily (morning and evening) brushing, the students follow the recommendations of the UFSBD [29].

This result is higher than that observed among Senegalese students [21], $29.1 \%$ of whom brush twice a day, $21.8 \% 3$ times a day and 57.5 once a day.

$18.48 \%$ of students brush their teeth for 3 minutes, $32.6 \%$ for 2 minutes and $48.92 \%$ for 1 minute. The duration of brushing is very important and effective for the removal of plaque. According to UFSBD [29], brushing for 43 to 57 seconds only removes about half of the newly formed plaque. Thus, rapid brushing can leave leftover food stuck to the teeth and therefore promote the proliferation of caries. This result remains different from that observed among Algerian students, $75 \%$ of whom surveyed exceeded three minutes of brushing [15]. UFSBD [29] explains that brushing should last at least two minutes, with the use of a fluoride toothpaste. These brushings should be completed with dental floss every evening [29]. 
For some students, the preferred brushing time is after dinner (40.9\%), with a significant difference from other brushing moments $(\mathrm{p}<0.05)$. While the most overlooked moment is after snacks $(28.6 \%)$ and after lunch (18\%), followed by the moment after breakfast (12.5\%), with no significant difference between skipped brushing moments $(\mathrm{p}<0.05)$. Thus, the teeth stay in contact with food for a long time. In this case, the rate of elimination of a cariogenic food from the mouth will be greater, which is an important factor in the genesis of caries. Oral bacteria ferment sugars and release acids that destroy teeth.

Only $33.9 \%$ of students follow WHO recommendations related to dental hygiene. This could be related to the socio-economic level of their parents. According to the recommendations of the UFSBD [29], it is necessary to check the dentist's annual dental condition, but most students do not consult him regularly, due to lack of medical cover and funds. According to WHO [30], conventional curative dental care is a significant economic burden for high-income countries, where $5 \%-10 \%$ of public health expenditure goes to oral health. In lowand middle-income countries like Morocco, public health programs targeting oral health are rare. And therefore, the cost of treatment is high, with the lack of medical coverage of students, this goes against the regular consultations of the dentist and therefore of oral health and well being not suitable.

The lifestyle also acts on oral health. Thus, a negative association was observed between alcohol consumption, of tobacco and the presence of caries among students. This result could be related to the low frequency of consumers of these substances in our population. In fact, alcohol consists essentially of ethanol, which after consumption is absorbed by the gastric and intestinal mucous membranes of the mouth. In the mouth, this can lead to bad breath and promote the growth of cariogenic bacteria [31]. Smoking also promotes the formation of bacterial plaque in the mouth, which increases the risk of cavities. This phenomenon is favored by poor dental hygiene.

Normally, adopting good eating habits is intended to ensure good general health, but also good oral health. The last food ingested is of great importance for the duration of acidification of the dental plaque. The consumption of a sweet food at the end of a meal decreases the $\mathrm{pH}$ and dental mineral surfaces demineralize [32].

\section{Conclusions}

It can be concluded from this work that:

- The type of food eaten during the day, eating habits as well as the frequency of ingestion is decisive factors in the prevention of tooth decay.

- The higher frequency of consumption of sugars and the greater the risk of dental caries.

- It must avoid nibbling because an unbalanced diet causes caries and dental erosions.

- Healthy eating habits, good dental hygiene and regular dental care are also needed to ensure good oral health, but also good general health. 


\section{Acknowledgements}

We thank all the students of the Faculty of Sciences Ben M'Sik, Hassan II University of Casablanca, who participated in the fieldwork.

\section{Conflicts of Interest}

The authors declare no conflicts of interest regarding the publication of this paper.

\section{References}

[1] OMS (Organisation mondiale de la Santé) (2003) Rapport sur la santé bucco-dentaire dans le monde: Poursuivre l'amélioration de la santé bucco-dentaire au XXI éme siècle: l'approche du Programme OMS de santé bucco-dentaire, Genève (Suisse), OMS. http://www.who.int/oral_health/media/en/orh_report03_fr.pdf

[2] Dental Health Foundation, Ireland (2018) Link between Oral \& General Health. https://www.dentalhealth.ie/dentalhealth/causes/general.html

[3] World Health Organization (2005) Bulletin of the World Health Organisation. Oral Health, General Health and Quality Of life. https://www.who.int/bulletin/volumes/83/9/editorial30905html/en/

[4] Boissonnat-Pelsy, H. and Tiebot, I. (2012) Estime de soi et santé bucco-dentaire. La Santé de l'Homme. INPES, 417, 29-31.

[5] Lardinois J., Guéders A. and Geerts S. (2009) Le point sur les données actuellement disponibles en épidémiologie de la carie chez les enfants belges. Revue Medicale De Liege, 64, 587-591.

[6] Kennedy, E.T. (2005) La situation globale de la nutrition: Que peuvent faire les états de l'industrie? Nutrition News for Africa. Journal of Nutrition, 135, 913-915.

http://www.hki.org/research/nna_storage/nna_abst_fr_avr15-05.htm https://doi.org/10.1093/jn/135.4.913

[7] Galmiche, F. (2011) Le rôle de l'alimentation dans la santé bucco-dentaire. Thèse présentée à Université Henri Poincare-Nancy, diplôme d'état de docteur en chirurgie dentaire, $1,165 \mathrm{p}$.

http://docnum.univ-lorraine.fr/public/SCDPHA_TD_2011_GALMICHE_FANNY. pdf

[8] Pollard, M.A., Duggal, M.S., Fayle, S.A., Toumba, K.J. and Curzon, M.E.J. (2016) Séries des monographies concises I L S I Europe. Stratégies de prévention de la carie dentaire, $30 \mathrm{p}$.

http://ilsi.eu/wp-content/uploads/sites/3/2016/06/C1995Car_PrevFren.pdf

[9] Shantinah, S.-D., Breiger, D., William, B.J. and Hasani, J.E. (1996) The Relationship of Sleep Problems and Sleep-Associated Feeding to Nursing Caries. Pediatric Dentistry, 18, 375-378.

[10] Haikel, Y. (2001) Thérapeutique étiopathogènique de la carie dentaire. In Encycl Méd Chir Elsevier Ed. Odontologie Paris, 23, 1-22.

[11] Selwitz, R.H., Ismail, A.I. and Pitts, N.B. (2007) Dental Caries. Lancet Jan 6; 369:51-9 SEOW WK. Biological Mechanisms of Early Childhood Caries. Community Dentistry and Oral Epidemiology, 26, 8-27.

[12] Latil, M. (2014) Informations de prévention bucco-dentaire délivrées par les médecins et les chirurgiens-dentistes en Midi-Pyrénées. Thèse présentée à UNIVERSITE TOULOUSE III-Paul-SABATIER. Faculté de Médecine, 48 p. 
http://thesesante.ups-tlse.fr/444/1/2014TOU31019.pdf

[13] Ministère de la Santé (2017) Une stratégie pour améliorer la santé bucco-dentaire des marocains. La tribune.

https://lnt.ma/sante-strategie-sante-bucco-dentaire-marocains/

[14] Hassoun, D. (1998) Précarité et état de santé bucco-dentaire. Rapport n 478 (biblio $\mathrm{n}^{\circ}$ 1249). Dépôt légal: décembre 1998. $70 \mathrm{p}$. http://www.irdes.fr/Publications/Rapports1998/rap1249.pdf

[15] Khaldi, T.El.M. (2010) Habitudes alimentaires et hygiène bucco-dentaire chez les étudiantes algériennes. Proposition d'un protocole d'étude avec pré enquête sur 125 étudiants. Mémoire de master en sciences alimentaire. Option: alimentation, nutrition et santé. Algérie, $88 \mathrm{p}$. https://docplayer.fr/4325224-Habitudes-alimentaires-et-hygiene-bucco-dentaire-ch ez-les-etudiants-algeriens-proposition-d-un-protocole-d-etude-avec-pre-enquete-su r-125-etudiants.html

[16] OMS Organisation Mondiale de la Santé (2015) Guideline: Sugars Intake for Adults and Children. Genève.

http://apps.who.int/iris/bitstream/handle/10665/149782/9789241549028_eng.pdf;se quence $=1$

[17] Djebli, R. (2017) Alimentation et santé bucco-dentaire. Thèse présentée à Université Toulouse III Paul Sabatier. Faculté de Chirurgie Dentaire, 76 p. http://thesesante.ups-tlse.fr/1694/1/2017TOU33041.pdf

[18] Johnson, R.K. and Frary, C. (2001) Choose Beverages and Foods to Moderate Your Intake of Sugars: The 2000 Dietary Guidelines for Americans-What's All the Fuss about? The Journal of Nutrition, 131, 2766S-2771S.

https://doi.org/10.1093/jn/131.10.2766S

[19] Miller, C. and Lasfargues, J. (2000) Diététique et prévention dentaire I. D Revue de presse, mars, 51-62.

[20] Stegeman, C.A. and Davis, J.R. (2005) The Dental Hygienist's Guide to Nutritional Care. 2 ème edition, Elsevier Saunders, St. Louis, 540 p.

[21] Kane, A.W., Faye, B., Toure, B., Sarr, M., Cisse, D., Diop, O. and Diallo, B. (2001) Habitudes d'hygiène orale et situation de la carie dentaire des étudiants: Enquête auprès de 150 étudiants en résidence universitaire à Dakar-Sénégal. Odonto-Stomatologie Tropicale, 93, 15-21.

[22] Esclassan, R. (2012) Etude des caries dentaires en fonction du sexe au sein d'individus adultes de la population médiévale (IXème-XVème siècles) de Vilarnau (Pyrénées-Orientales) et synthèse sur l'usure. Thèse présentée à l'université de Toulouse Paul Sabatier. Bibliothèque de l'UPS. 305 p. http://thesesups.ups-tlse.fr/1607/1/2012TOU30027.pdf

[23] Kaoutar, K., Hilali, M.K. and Loukid, M. (2013) La situation de la carie dentaire chez les adolescents de la Wilaya de Marrakech (Maroc). Antropo, 29, 101-108.

[24] Ministère de la santé (Maroc) (1990) Programme national de santé bucco-dentaire. $4 \mathrm{p}$.

http://associationdesmedecins.ma/wp-content/uploads/2013/12/Sante-Buccodentair e.pdf

[25] Frank, R. (1994) Cariogénicité des aliments accusés: Les glucides. Mais tout dépend des circonstances.... la lettre de P Institut Danone, 18, 3-9.

[26] Dargent-Pare, C. and Levy, G. (2001) Odontologie in Basdevant, A., Laville, M. et Lerebours, E. Traité de nutrition clinique de l'adulte. Médecine-Sciences, Flammarion, 723, 609-612. 
[27] AFSSAPS (Agence Française de sécurité sanitaire des produits de santé) (2008) Mise au point. Utilisation du fluor dans la prévention de la carie dentaire avant l'âge de 18 ans.

http://ansm.sante.fr/var/ansm_site/storage/original/application/7db1d82db7f5636b 56170f59e844dd3a.pdf

[28] Belkaab, N. (2006) Propositions pour une réorganisation de l'offre publique de soins bucco-dentaires au Maroc. Royaume du Maroc, Ministere de la santé. Institut Nationale d'administration sanitaire. Centre collaborateur de l'OMS. Huitième cours national de formation en Administration sanitaire et santé publique (2004-2006). 90 p.

http://fulltext.bdsp.ehesp.fr/Inas/Memoires/massp/sp/2006/7105.pdf

[29] UFSBD (Union Française pour la Santé Bucco-Dentaire) (2013) Nouvelles recommandations L'UFSBD réactualise ses stratégies de prévention.

http://www.ufsbd.fr/wp-content/uploads/2013/11/Recos-espace-PRO.pdf

[30] OMS (Organisation mondiale de la Santé) (2012) Santé bucco-dentaire Aide-mémoire $\mathrm{N}^{\circ}$ 318. http://www.who.int/mediacentre/factsheets/fs318/fr/

[31] Prestifilippo, J.P., Fernandez-Solari, J., Medina, V., Rettori, V. and Elverdin, J.C. (2009) Role of the Endocannabinoid System in Ethanol Induced Inhibition of Salivary Secretion. Alcohol, 44, 443-448. https://doi.org/10.1093/alcalc/agp040

[32] Boudafdafa, S. (2015) Alimentation et santé bucco-dentaire. Thèse soutenue pour l'obtention du Doctorat en Médecine dentaire, Université HASSAN II de Casablanca Faculté de Médecine dentaire. 154 p. 